Editorial

\title{
Acknowledgement to Reviewers of OBM Genetics in 2021
}

OBM Genetics Editorial Office

LIDSEN Publishing Inc., 2000 Auburn Drive, One Chagrin Highlands, Suite 200, Beachwood, OH, USA;

E-Mail: genetics@lidsen.com

OBM Genetics

2022, volume 6 , issue 1

doi:10.21926/obm.genet.2201144
Received: January 05, 2022

Accepted: January 06, 2022

Published: January 06, 2022

\begin{abstract}
The editors of $O B M$ Genetics would like to express their sincere gratitude to the following reviewers for assessing manuscripts in 2021 . We greatly appreciate the contribution of expert reviewers, which is crucial to the journal's editorial process. We aim to recognize reviewer contributions through several mechanisms, of which the annual publication of reviewer names is one. Reviewers receive a voucher entitling them to a discount on their next LIDSEN publication and can download a certificate of recognition directly from our submission system. Additionally, reviewers can sign up to the service Publons (https://publons.com) to receive recognition. Of course, in these initiatives we are careful not to compromise reviewer confidentiality. Many reviewers see their work as a voluntary and often unseen part of their role as researchers. We are grateful to the time reviewers donate to our journals and the contribution they make.
\end{abstract}

The editors of $O B M$ Genetics would like to express their sincere gratitude to the following reviewers for assessing manuscripts in 2021.

We greatly appreciate the contribution of expert reviewers, which is crucial to the journal's editorial process. We aim to recognize reviewer contributions through several mechanisms, of which the annual publication of reviewer names is one. Reviewers receive a voucher entitling them to a discount on their next LIDSEN publication and can download a certificate of recognition directly from our submission system. Additionally, reviewers can sign up to the service Publons (https://publons.com) to receive recognition. Of course, in these initiatives we are careful not to

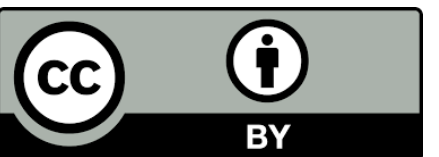

(C) 2022 by the author. This is an open access article distributed under the conditions of the Creative Commons by Attribution License, which permits unrestricted use, distribution, and reproduction in any medium or format, provided the original work is correctly cited. 
compromise reviewer confidentiality. Many reviewers see their work as a voluntary and often unseen part of their role as researchers. We are grateful to the time reviewers donate to our journals and the contribution they make.

If you are interested in becoming a reviewer for OBM Genetics, see the link at the bottom of the webpage http://lidsen.com/joinus.

The following reviewed for OBM Genetics in 2021:

\begin{tabular}{|l|l|l|}
\hline Bacolla, Albino & lourov, Ivan & Reed, B. \\
\hline Benincasa, Giuditta & lourov, Ivan Y & Rogers, Jeffrey \\
\hline Boardman, Felicity Kate & Jurivich, Donald A. & Rousseau, François \\
\hline Chai, Yourong & Kamilari, Maria & Rumi, Mohammad A. Karim \\
\hline Charmet, Gilles & Laberge, Anne-Marie & Sharma, Madan Mohan \\
\hline Chudleigh, Jane & Laronda, Monica M. & Siddique, Hifzur R \\
\hline Coleman, Leon G. & Larson, Nicholas B. & Singh, Nisha \\
\hline Evans, Mark I. & Li, Feng & Sirotkin, Alexander V. \\
\hline Facchin, Gianella & Maiorano, Amanda & Somma, Stefania \\
\hline Geraedts, Jeop & Merrick, B. Alex & Sontag, Marci K. \\
\hline Gonska, Tanja & Metzler, Ingrid & Terlizzi, Vito \\
\hline Greed, Lawrence & Miller, Fiona & van Heetvelde, Mattias \\
\hline Hashiloni-Dolev, Yael & Mounier, Aurélien & Van Maarle, Merel \\
\hline Helms, Volkhard & Narod, Steven A. & Xu, Shutu \\
\hline Holak, Tad A. & Ohm, Joyce & Yao, Shuzhong \\
\hline Horn, Ruth & Pavlov, Youri I. & Zeng, Xuehuo \\
\hline Hubáček, Jaroslav Alois & Pop, Laura Ancuţa & Zou, Mengchen \\
\hline Ibrahim, Mohamed F.M. & Raraigh, Karen S. & Zou, Ying \\
\hline
\end{tabular}

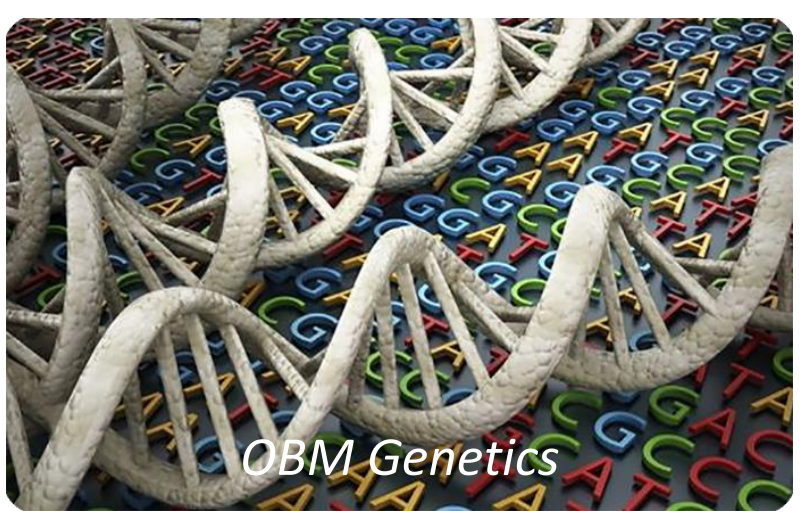

Enjoy OBM Genetics by:

1. Submitting a manuscript

2. Joining in volunteer reviewer bank

3. Joining Editorial Board

4. Guest editing a special issue

For more details, please visit:

http://www.lidsen.com/journals/genetics 